\title{
Dielectrophoresis for manipulation of micro/nano particles in microfluidic systems
}

\author{
C. Zhang • K. Khoshmanesh • A. Mitchell • \\ K. Kalantar-zadeh
}

Published online: 3 September 2009

(C) Springer-Verlag 2009

Erratum to: Anal Bioanal Chem

DOI 10.1007/s00216-009-2922-6

Unfortunately, there was a mistake in Equations (12) and (13).

The corrected equations for (12) and (13) are:

$f_{C M-\text { cylindrical }}=\frac{\varepsilon_{p}^{*}-\varepsilon_{m}^{*}}{\varepsilon_{m}^{*}}$,

$f_{C M-\text { spherical }}=\frac{\varepsilon_{p}^{*}-\varepsilon_{m}^{*}}{\varepsilon_{p}^{*}+2 \varepsilon_{m}^{*}}$,

The online version of the original article can be found at http://dx.doi. org/10.1007/s00216-009-2922-6.

C. Zhang $\cdot$ A. Mitchell $\cdot$ K. Kalantar-zadeh $(\square)$

School of Electrical and Computer Engineering, RMIT University,

Melbourne, Australia

e-mail: kourosh.kalantar@rmit.edu.au

K. Khoshmanesh

School of Engineering, Deakin University,

Melbourne, Australia 